\title{
EFEKTIVITAS TERAPI WATER BASED EXERCISE TERHADAP KEMAMPUAN MOTORIK PADA PASIEN PASCA STROKE
}

\author{
Shabrina Riandini ${ }^{1}$ \\ ${ }^{1}$ Program Pendidikan Dokter Fakultas Kedokteran Universitas Lampung
}

\begin{abstract}
Effectiveness of Water-Based Exercise Therapy on Motor Ability in Post-Stroke Patients. Stroke during the last 15 years has become the most common cause of death in the world, besides stroke is also a cause of physical disability in the elderly and productive age. Risk factors for stroke are reduced to factors that can be modified and cannot be modified. The most common factor that triggers a stroke is hypertension. Stroke has a variety of symptoms depending on which part of the brain is disrupted. As a result of stroke most experienced by patients including hemiparesis and unable to walk without the help of others. So that comprehensive management needs to involve medical rehabilitation to return the patient's ability to take care of himself and carry out daily activities without the help of others. Medical rehabilitation to improve motor skills is divided into 2 types, namely water-based exercise and land-based exercise. Patients undergoing Waterbased exercise therapy have increased walking ability and better balance than patients who only undergo land-based exercise. By combining water-based exercise and land-based exercise can increase muscle strength, quality of life, and the sustainability of patient therapy because it is more fun.
\end{abstract}

Keywords : Clinical Rehabilitation, water based exercise, stroke, motor

\begin{abstract}
Abstrak: Efektivitas Terapi Water Based Exercise terhadap Kemampuan Motorik pada Pasien Pasca Stroke. Stroke selama 15 tahun terakhir menjadi penyebab kematian terbanyak di dunia, selain itu stroke juga merupakan penyebab disabilitas fisik pada lansia dan usia produktif. Faktor risiko terjadinya stroke dibagi menjadi faktor yang dapat dimodifikasi dan tidak dapat dimodifikasi. Faktor yang paling sering menjadi pemicu terjadinya stroke adalah hipertensi. Stroke memiliki berbagai gejala tergantung dari bagian otak mana yang mengalami gangguan. Akibat stroke yang paling banyak dialami pasien diantaranya hemiparesis dan tidak mampu berjalan tanpa bantuan orang lain. Sehingga tatalaksana yang komprehensif perlu melibatkan rehabilitasi medik dengan tujuan mengembalikan kemampuan pasien dalam mengurus dirinya sendiri dan melakukan aktivitas sehari-hari tanpa bantuan orang lain. Rehabilitasi medis untuk meningkatkan kemampuan motorik dibagi menjadi 2 tipe, yaitu water based exercise dan land based exercise. Pasien yang menjalani terapi water based exercise memiliki peningkatan kemampuan berjalan serta keseimbangan yang lebih baik dibandingkan pasien yang hanya menjalani land based exercise. Dengan menggabungkan water based exercise dan land based exercise mampu meningkatkan kekuatan otot, kualitas hidup, serta keberlanjutan terapi pasien karena lebih menyenangkan.
\end{abstract}

Kata Kunci : Rehabilitas medik, water based exercise, stroke, motorik 


\section{PENDAHULUAN}

$$
\text { Dunia }
$$

yang

semakin

berkembang diiringi dengan perubahan gaya hidup masyarakatnya menyebabkan perubahan pola penyakit dari penyakit menular menjadi penyakit tidak menular. Menurut data World Health Organization atau WHO, pada tahun 2000 penyebab kematian terbanyak didominasi oleh penyakit tidak menular seperti penyakit paru obstruktif kronis, kanker saluran pernapasan, diabetes, penyakit jantung, dan stroke. Seiring dengan pergeseran tersebut, stroke tetap menjadi peringkat kedua sebagai penyebab kematian terbanyak di dunia selama 15 tahun terakhir. Dengan peningkatan data dari sekitar 4,5 juta kematian pada tahun 2000 menjadi 4,8 juta kematian pada tahun 2016 (World Health Organization, 2018). Selain itu, menurut data dari World Stroke Organization, pada tahun 2016 terdapat 13,6 juta kasus stroke baru pertahunnya dan 1 dari 4 orang berisiko untuk mengalami stroke (World Stroke Organization, 2019).

Di Indonesia juga mengalami hal yang sama, yaitu terus terjadi peningkatan pada penyakit tidak menular sebagai penyebab kematian. Dilihat dari tahun 1990 kematian yang disebabkan oleh penyakit tidak menular hanya sekitar $37 \%$ terus meningkat hingga pada tahun 2014 mencapai angka 71\%. Pada tahun 2014 penyebab kematian utama di segala umur paling banyak disebabkan oleh stroke dengan jumlah $21,1 \%$ atau sekitar 1,2 juta (Kementrian Kesehatan Republik Indonesia, 2016).

Stroke adalah sindrom klinis yang ditandai dengan adanya defisit neurologis serebral fokal atau global yang berkembang dengan cepat dan berlangsung minimal dalam 24 jam atau menyebabkan kematian yang semata-mata disebabkan oleh kejadian vaskular, baik perdarahan spontan pada otak (stroke perdarahan) maupun suplai darah yang inadekuat pada bagian otak (stroke iskemik) karena akibat aliran darah yang rendah, trombosis atau emboli yang berkaitan dengan penyakit pembuluh darah (arteri dan vena), jantung, dan darah. Kebanyakan kasus stroke terjadi pada orang yang sudah berumur 65 tahun ke atas atau lansia dan dapat menyebabkan kecacatan atau disabilitas. Pasien stroke dapat mengalami defisit neurologi fokal maupun global. Defisit neurologi fokal ditandai dengan kelemahan pada salah satu sisi tubuh, kesulitan menelan, sulit mengekspresikan bahasa lisan, gangguan sensorik pada salah satu sisi tubuh, gangguan penglihatan, serta mudah lupa dan sulit dalam melakukan aktivitas sehari-hari. Sedangkan defisit neurologis non fokal atau global ditandai dengan kelemahan tubuh secara menyeluruh, sensasi kepala terasa ringan, perubahan atau penurunan kesadaran, inkontinensia merle atau feses, kebingungan serta tinitus (Setiati et al., 2014).

Meskipun tidak semua pasien yang mengalami stroke berujung kematian, namun menurut data dari Stroke Association, stroke merupakan salah satu penyebab disabilitas terbanyak karena lebih dari 50\% pasien pasca stroke mengalami disabilitas. Disabilitas pada pasien stroke ditandai dengan penurunan kemampuan dalam melakukan aktivitas sehari-hari (Stroke Association, 2016). Hal ini sejalan dengan penelitian dari Yang et al, yang menunjukan bahwa $45 \%$ pasien pasca stroke mengalami disabilitas sehingga diperlukan tatalaksana yang adekuat serta rehabilitasi yang tepat untuk mengurangi disabilitas pada pasien pasca stroke (Yang et al., 2016).

Rehabilitasi merupakan aspek penting dalam tatalaksana yang merupakan program esensial untuk mengoptimalisasi kemampuan pasien pasca stroke. Rehabilitasi pasca stroke merupakan proses yang kompleks dan perlu melibatkan beberapa tenaga kesehatan dari berbagai bidang dan beberapa pendekatan, itu semua bergantung pada masing-masing defisit pasien (Belegaje, 2017). Rehabilitasi untuk memulihkan kemampuan motorik dapat dilakukan melalui dua 
macam latihan, yaitu latihan konvensional yang sudah ada dalam klinik dan rumah sakit dan latihan akuatik yang dilakukan di air(Trisnowiyanto, 2012).

Menurut Seidel, pasien pasca stroke yang mengikuti rehabilitasi selama 12 bulan mengalami peningkatan kemampuan fungsional yang signifikan (Seidel, 2019). Sejalan dengan penelitian yang dilakukan Chaiyawat menunjukan pasien yang melakukan rehabilitasi awal selama 6 bulan pasca stroke menunjukan peningkatan fungsi, peningkatan kualitas hidup, serta mengurangi disabilitas (Chaiyawat \& Kulkantrakorn, 2012). Hal tersebut menunjukan pentingnya rehabilitasi dalam pemulihan pasien pasca stroke. Rehabilitasi untuk memulihkan kemampuan motorik dapat dilakukan melalui dua macam latihan, yaitu latihan konvensional yang sudah ada dalam klinik dan rumah sakit dan latihan akuatik yang dilakukan di air. Menurut penelitian menunjukan bahasa dengan melakukan latihan akuatik selama 2 kali per minggu selama 6 minggu akan meningkatkan kemampuan motorik pasien pasca stroke dengan lebih baik jika dibandingkan dengan metode konvensional (Trisnowiyanto, 2012).

\section{METODE}

Penelitian ini merupakan artikel review ilmiah yang dilakukan dengan mengumpulkan artikel ilmiah penelitian sebelumnya untuk mendapatkan informasi serta membuat ringkasan.

\section{HASIL DAN PEMBAHASAN}

Stroke merupakan peringkat kedua sebagai penyebab kematian di dunia dan merupakan penyebab utama disabilitas atau kecacatan fisik pada lansia dan usia produktif. Menurut data WHO, dapat disimpulkan bahwa semakin tinggi pendapatan suatu negara maka semakin besar persentase kematian dengan stroke sebagai penyebabnya. Pada negara dengan pendapatan rendah sekitar 40 per
100.000 populasi dunia, sedangkan pada negara dengan pendapatan menengah ke atas kematian akibat stroke mencapai 110 per 100.000 populasi. Namun pada negara dengan pendapatan tinggi kematian akibat stroke hanya sekitar 60 per 100.000 populasi (World Health Organization, 2018). Selain menyebabkan kematian stroke juga dapat menyebabkan kecacatan fisik pada penderitanya. Menurut penelitian Yang, setelah dilakukan follow-up selama 5 tahun pasca serangan stroke, didapatkan dari 893 pasien pasca stroke 402 diantaranya mengalami kecacatan fisik. Hal ini berkaitan dengan faktor usia yang lebih tua, berjenis kelamin perempuan, disertai penyakit komorbid seperti diabetes dan penyakit jantung, riwayat serangan stroke sebelumnya, skor NIHSS yang lebih tinggi, tingkat pendidikan yang lebih rendah, serta kebiasaan konsumsi alkohol (Yang et al., 2016).

Di Indonesia sendiri prevalensi stroke terus mengalami peningkatan. Menurut data Riskesdas, pada tahun 2013 prevalensi stroke adalah 7 dari 1000 populasi penduduk. Namun pada tahun 2018 angka tersebut meningkat hingga mencapai 10.9 dari 1000 populasi penduduk. Prevalensi akan meningkat seiring dengan bertambahnya usia, dengan mayoritas penderita stroke berusia $>75$ tahun dengan tempat tinggal di perkotaan (Riskesdas, 2018). Tingginya prevalensi tersebut menyebabkan tingginya juga angka kematian akibat stroke. Menurut WHO, stroke merupakan penyebab kematian prematur pertama di Indonesia diikuti dengan penyakit lain seperti penyakit jantung iskemik, tuberkulosis, dan penyakit lainnya (Kementerian Kesehatan Republik Indonesia \& WHO, 2017).

Stroke merupakan sindrom klinis yang ditandai dengan adanya defisit neurologis serebral fokal atau global yang berkembang dengan cepat dan berlangsung minimal dalam 24 jam atau menyebabkan kematian yang semata-mata disebabkan oleh kejadian 
vaskular. Penyebab stroke terbagi menjadi 2 kategori, yaitu iskemik dan hemoragik. Stroke iskemik terbagi menjadi 2, aterosklertik yang biasa terjadi pada lansia, dan stroke iskemik embolik yang lebih sering pada pasien dengan atrial fibrilasi. Sedangkan stroke hemoragik terdiri dari intracranial haemorrhages dan subarachnoid haemorrhages yang disebabkan ruptur pada aneurisma. Stroke memiliki gejala klinis yang bervariasi, tergantung bagian otak mana yang sirkulasinya terganggu (Setiati et al., 2014; Wittenauer \& Smith, 2012). Terdapat beberapa macam tes skrining untuk mendeteksi adanya gejala stroke, salah satunya adalah FAST. FAST merupakan singkatan dari facial weakness, arm weakness, speech problems, dan time to call emergency (Parmar, 2018).

Untuk menegakan diagnosis stroke, semua pasien yang mengalami gejala stroke harus melakukan pemeriksaan CT (Computed Tomography) scan tanpa kontras atau MRI (Magnetic Resonance Imaging). Tujuan utama dilakukan pemeriksaan ini adalah untuk membedakan antara stroke iskemik atau hemoragik serta untuk menapis kemungkinan adanya lesi non iskemik pada sistem saraf pusat. MRI memiliki resolusi yang lebih baik serta lebih sensitif untuk mendeteksi stroke iskemik akut, namun CT scan lebih cepat, terjangkau, serta dapat dilakukan pada pasien dengan implanted device (Yew et al., 2015).

Faktor risiko stroke dibagi menjadi dua kategori yaitu faktor risiko yang tidak dapat dimodifikasi dan dapat dimodifikasi. Faktor risiko yang tidak dapat dimodifikasi diantaranya usia, jenis kelamin, dan riwayat keluarga. Faktor risiko yang dapat dimodifikasi adalah hipertensi, diabetes melitus, obesitas, hiperkolesterolemia, atrial fibrilasi, dan merokok (Mutiarasari, 2019). Dari semua faktor risiko stroke, yang paling banyak berperan dalam angka kejadian stroke adalah hipertensi. Hipertensi yang tidak terkontrol menyebabkan stroke pada pembuluh darah kecil terutama pada bagian cerebellum, pons, dan thalamus. Sebagai pencegahan maka perlu dilakukan perubahan pada faktor risiko yang masih dapat dimodifikasi, sehingga orang yang berisiko tidak perlu mengalami serangan stroke (Khaku, 2020).

Disabilitas sebagai dampak stroke pada pasien sangat beragam. Menurut penelitian Go, setelah dilakukan observasi selama 6 bulan pada pasien pasca stroke yang mengalami serangan stroke pada usia lebih dari 65 tahun dan bertahan. Sekitar $50 \%$ pasien mengalami hemiparesis, 30\% tidak dapat berjalan tanpa bantuan, $40 \%$ mengalami defisit kognitif, $35 \%$ mengalami gejala depresi, $19 \%$ afasia, $26 \%$ memerlukan bantuan dalam melakukan aktivitas fisik, dan $26 \%$ memerlukan perawatan di rumah (Go et al., 2014). Sehingga bagi pasien yang mengalami disabilitas atau kecacatan fisik diperlukan intervensi rehabilitasi medis untuk mengembalikan kemampuan pasien dalam mengurus dirinya sendiri dan melakukan aktivitas sehari-hari tanpa memerlukan bantuan orang lain terutama pada fungsi motorik yang merupakan kecacatan terbanyak pada pasien pasca stroke (Belegaje, 2017).

Menurut penelitian Eyvaz et al yang dilakukan pada 60 sampel yang di follow-up setelah diberikan terapi selama 6 minggu dengan 5 kali pertemuan/minggu. Pada 30 pasien diberikan water based exercise dan 30 pasien lainnya diberikan land based exercise. Setelah dianalisis, pada pasien dengan terapi water based exercisememiliki kemampuan keseimbangan baik statis maupun dinamis yang lebih baik dibandingkan pasien dengan terapi land based exercise. Namun, pada pengukuran kecepatan berjalan keduanya memiliki hasil yang seimbang. Selain itu dengan mengombinasikan water based exercise dan land based exercise dapat meningkatkan kekuatan otot serta kualitas hidup pasien dan keberlanjutan terapi rehabilitasi pasien 
karena lebih menyenangkan (Eyvaz et al., 2018).

$\begin{array}{cll}\text { Sejalan } & \text { dengan } & \text { penelitian } \\ \text { sebelumnya } & \text { pada } & \text { penelitian }\end{array}$
randomized control trial yang dilakukan pada 28 penderita stroke yang mengalami gangguan berjalan dan keseimbangan dilakukan perbandingan antara pemberian terapi akuatik dengan terapi konvensional. Setelah 4 minggu menjalani terapi, didapatkan peningkatan skor berg balance scale, functional reach test, 2-minutes walk test, dan timed up and go test pada kedua jenis terapi. Namun pada hidroterapi didapatkan peningkatan signifikan pada functional reach test dan 2 minutes walk test dibandingkan dengan terapi konvensional. Sehingga dapat disimpulkan bahwa hydrotherapy lebih efektif dalam meningkatkan kemampuan berjalan serta keseimbangan pada pasien stroke (Zhu et al., 2015).

Studi systematic review dan meta analisis yang dilakukan oleh Marinho-buzelli et aldan Iatridou et al menunjukan bahwa terdapat peningkatan yang signifikan terhadap mobilitas serta keseimbangan postural pada pasien pasca stroke. Tetapi studi yang dilakukan oleh Marinho-buzelli et al meskipun terdapat peningkatan kemampuan mobilisasi, tetapi belum terdapat bukti yang memadai untuk menyimpulkan bahwa terapi akuatik lebih efektif dibandingkan terapi konvensional (Iatridou et al., 2017; Marinho-buzelli et al., 2015).

Penelitian yang dilakukan Chan et al pada 32 pasien pasca stroke dengan usia, bagian sisi tubuh yang terkena stroke, waktu serangan stroke. Penelitian dilakukan dengan metode single-blind randomized controlled study dengan 17 pasien diberi terapi akuatik dan konvensional lalu 15 pasien hanya diberi terapi konvensional. Hasilnya menunjukan bahwa pasien dengan terapi akuatik dan konvensional memiliki perubahan yang lebih signifikan dibandingkan dengan terapi konvensional saja dalam hal keseimbangan dan mobilitas. Akibat daya apung air pada terapi akuatik, menyebabkan penurunan beban pada kaki serta membuat latihan keseimbangan menjadi lebih mudah bagi pasien, serta rasa takut untuk terjatuh juga berkurang (Chan et al., 2016).

Menurut penelitian Furnari et al, yang dilakukan pada 40 pasien pasca stroke dengan hemiparesis dan spastisitas. Setelah diberikan terapi selama 8 minggu dengan kelompok eksperimen diberikan water based exercise serta land based exercise dan kelompok kontrol hanya diberikan land based exercise. Keduanya memiliki perkembangan yang signifikan, namun pada pasien dengan terapi akuatik memiliki hasil yang lebih baik dalam peningkatan gait dan keseimbangan (Furnari et al., 2014). Sedangkan menurut penelitian Trisnowiyanto, menunjukan bahwa pasien stroke yang mengalami kecacatan fisik memiliki tingkat pemulihan kemampuan motorik yang lebih besar pada terapi akuatik dibandingkan dengan terapi konvensional. Hal ini dinilai dari kemampuan keseimbangan duduk statis, keseimbangan berdiri statis dan kemampuan ambulasi. Pada latihan akuatik, tubuh pasien dapat berdiri dengan lebih mudah dan lebih lama dibandingkan terapi konvensional. Hal ini dikarenakan dalam air tubuh mendapatkan bantuan dari tahanan air yang akan menyangga tubuh saat berdiri dalam air. Sedangkan pada latihan konvensional lebih memerlukan bantuan agar dapat berdiri dan berjalan dengan leluasa (Trisnowiyanto, 2012).

\section{KESIMPULAN}

Stroke merupakan salah satu penyebab disabilitas fisik terutama pada lansia dan usia produktif. Rehabilitasi pasca stroke sangat diperlukan dalam tatalaksana guna mengembalikan kemampuan pasien dalam mengurus dirinya sendiri terutama pada fungsi motorik. Rehabilitasi pasca stroke dapat dilakukan dengan 2 tipe, yaitu water based exercise dan land based exercise. Water based exercise lebih 
signifikan dalam meningkatkan kemampuan mobilisasi pada pasien pasca stroke. Selain itu, water based exercise juga meningkatkan keseimbangan pada pasien baik keseimbangan statis maupun dinamis dan ketakutan yang dirasakan pasien akan terjatuh menjadi lebih sedikit. Hal itu akibat faktor daya apung air. Dengan menggabungkan terapi water based exercise dan land based exercise mampu meningkatkan kekuatan otot, kualitas hidup pasien, serta keberlanjutan terapi pasien karena lebih menyenangkan.

\section{DAFTAR PUSTAKA}

Belegaje, S. (2017). Stroke Rehabilitation. Continuum Review Article, 23(1), 238-253. https://doi.org/10.1212/CON.000 0000000000423

Chaiyawat, P., \& Kulkantrakorn, K. (2012). Effectiveness of home rehabilitation program for ischemic stroke upon disability and quality of life: A randomized controlled trial, 114, 866-870. https://doi.org/10.1016/j.clineuro .2012.01.018

Chan, K., Phadke, C. P., Stremler, D., Suter, L., Pauley, T., Ismail, F., ... Pauley, T. (2016). Topics in Stroke Rehabilitation The effect of water-based exercises on balance in persons post-stroke: a randomized controlled trial. Topics in Stroke Rehabilitation, 1-8. https://doi.org/10.1080/1074935 7.2016.1251742

Eyvaz, N., Dundar, U., \& Yesil, H. (2018). Effects of water-based and land-based exercises on walking and balance functions of patients with hemiplegia. NeuroRehabilitation, 43, 237-246. https://doi.org/10.3233/NRE182422

Furnari, A., Salvatore, R., Gervasi, G., Fauci-Belponer, F. La, Marzo, A., Berbiglia, F., ... Bramanti, P. (2014). Is hydrokinesitherapy effective on gait and balance in patients with stroke? A clinical and baropodometric investigation.
Brain Injury, 28(8), 1109-1114. https://doi.org/10.3109/0269905 2.2014.910700

Go, A. S., Mozaffarian, D., Roger, V. L., Benjamin, E. J., Berry, J. D., Blaha, M. J., ... Woo, D. (2014). AHA Statistical Update Heart Disease and Stroke Statistics 2014 Update A Report From the American Heart Association WRITING GROUP MEMBERS, 129(3), 28-292. https://doi.org/10.1161/01.cir.00 00441139.02102 .80

Iatridou, G., Pelidou, H., Varvarousis, D., Stergiou, A., Beris, A., \& Givissis, P. (2017). The effectiveness of hydrokinesiotherapy on postural balance of hemiplegic patients after stroke: a systematic review and meta-analysis. Clinical Rehabilitation, 1-11. https://doi.org/10.1177/0269215 517748454

Kementerian Kesehatan Republik Indonesia, \& WHO. (2017). State of Health Inequality. WHO.

Kementerian Kesehatan Republik Indonesia. (2016). Pencegahan dan Pengendalian Penyakit Tidak Menular di Indonesia. Kemenkes RI.

Khaku, A. S. (2020). Cerebrovascular Disease (Stroke). StatPearls Publishing. Retrieved from https://www.ncbi.nlm.nih.gov/boo ks/NBK430927/

Marinho-buzelli, A. R., Bonnyman, A. M., \& Verrier, M. C. (2015). The effects of aquatic therapy on mobility of individuals with neurological diseases: a systematic review. Clinical Rehabilitation.

https://doi.org/10.1177/0269215 514556297

Mutiarasari, D. (2019). Ischemic Stroke: Symptoms, Risk Factors, and Prevention. Medika Tadulako, 6(1), 60-73.

Parmar, P. (2018). Stroke: classification and diagnosis. Pharmaceutical Journal, 10(1). https://doi.org/10.1211/CP.2018. 
20204150

Riskesdas. (2018). HASIL UTAMA RISKESDAS 2018. Kemenkes RI.

Seidel, G. (2019). Quality of Life and Disability After Severe Stroke and Early Neurological Rehabilitation. Nervenarzt, 90(10), 1031-1036. https://doi.org/10.1007/s00115019-0740-4

Setiati, S., Alwi, I., \& Sudoyo, A. (2014). Buku Ajar IImu Penyakit Dalam. Jakarta: Interna Publishing.

Stroke Association. (2016). Stroke Statistics 2015. Retrieved July 23, 2020, from https://www.stroke.org.uk/sites/d efault/files/stroke_statistics_2015 .pdf

Trisnowiyanto, B. (2012). Pengaruh Latihan Konvensional Dan Akuatik Pada Pemulihan Kemampuan Motorik Penyandang Hemiparesis Pasca Stroke Infark. In Prosiding Seminar Nasional Peran Pendidikan Jasmani dalam Menyangga Interdisipliner IImu Keolahragaan (pp. 541-581). Malang: Universitas Negeri Malang.

Wittenauer, B. R., \& Smith, L. (2012). Ischaemic and Haemorrhagic Stroke. WHO.

World Health Organization. (2018). The Top 10 Causes of Death. Retrieved July 23, 2020, from https://www.who.int/newsroom/fact-sheets/detail/the-top10-causes-of-death

World Stroke Organization. (2019). Global Stroke Fact Sheet. Retrieved July 23, 2020, from https://www.worldstroke.org/assets/downloads/WS O_Global_Stroke_Fact_Sheet.pdf Yang, Y., Shi, Y., Zhang, N., Wang, S., Ungvari, G. S., Ng, C. H., ... Xiang, Y. (2016). The Disability Rate of 5-Year Post-Stroke and Its Correlation Factors: A National Survey in. PLOS One, 1-9. https://doi.org/10.1371/journal.p one.0165341

Yew, K. S., Medicine, F., Cheng, V. E. M., \& Angeles, L. (2015).
Diagnosis of Acute Stroke. American Family Physician, 91(8), 528-536.

Zhu, Z., Cui, L., Yin, M., Yu, Y., Zhou, X., Wang, H., \& Yan, H. (2015). Hydrotherapy vs . conventional land-based exercise for improving walking and balance after stroke: A randomized controlled trial. Clinical Rehabilitation, 1-7. https://doi.org/10.1177/0269215 515593392 